\title{
УД-II-1
}

\section{ПРИМЕНЕНИЕ ИК ТЕРМОГРАФИИ ДЛЯ ИЗУЧЕНИЯ ТЕПЛОВЫХ ЭФФЕКТОВ В ПРОЦЕССАХ ГИДРАТАЦИИ-ДЕГИДРАТАЦИИ ОКИСИ АЛЮМИНИЯ РАЗНОГО ФАЗОВОГО СОСТАВА И МОРФОЛОГИИ}

\author{
Вайнер Б.Г. ${ }^{1,2}$, Володин А.М. ${ }^{3}$
}

${ }^{1}$ Институт физики полупроводников им. А.В. Ржанова СО РАН, Новосибирск, Россия

${ }^{2}$ Новосибирский национальный исследовательский государственный университет, Новосибирск, Россия

${ }^{3}$ ФГБУН ФИЦ Институт катализа им. Г. К. Борескова СО РАН, Новосибирск, Россия boris-stmt@yandex.ru

DOI: 10.26902/ASFE-11_29

Оксиды алюминия разного фазового состава и морфологии принадлежат к основным твердотельным системам, используемым в современных адсорбционных и каталитических технологиях. Наличие аморфного $\mathrm{Al}_{2} \mathrm{O}_{3}$ в материалах, применяемых в качестве носителей для катализаторов, обычно нежелательно в силу его нестабильности и высокой реакционной способности по отношению к молекулам газовой фазы. По этой причине получение информации о содержании аморфной компоненты в оксидах алюминия имеет важное практическое значение. Актуальным представляется поиск новых экспериментальных подходов, позволяющих детектировать наличие аморфной фазы в образцах оксидов алюминия.

Адсорбция молекул воды на поверхности твердого тела вызывает разогрев в силу выделения теплоты фазового перехода, а десорбция соответственно, охлаждение. Этот эффект был использован в настоящей работе. Впервые проведено

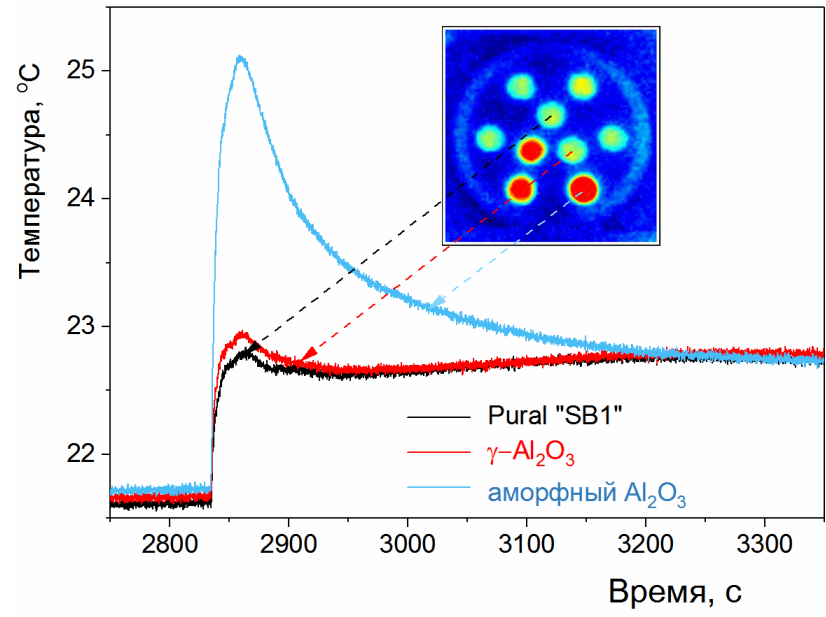

Рис.1. Тепловые эффекты при взаимодействии оксидов алюминия с водяным паром. На вставке термограмма библиотеки из девяти образцов, измеренная в момент времени около $2950 \mathrm{c}$. исследование процессов гидратации-дегидратации оксидов алюминия различного фазового состава при комнатной температуре с использованием тепловизионной техники, высокие экспериментальные возможности которой подробно представлены в $[1,2]$. Регистратором тепловыделения и поглощения тепла служил матричный тепловизор ТКВр-ИФП с температурной чувствительностью $0.03{ }^{\circ} \mathrm{C}$ и быстродействием 100 кадров в секунду.

Характеристики адсорбции, зарегистрированные прибором при напуске влажного кислорода в реактор показаны на рис. 1. Хорошо видно, что структуры, содержащие аморфную фазу, проявляют гораздо больший температурный отклик на процедуру гидратации, чем окристаллизованные образцы прекурсора (Pural "SB1") и $\gamma-\mathrm{Al}_{2} \mathrm{O}_{3}$.

Показано, что при наличии аморфной фазы существенный вклад в регистрируемый тепловой эффект может давать протекающая в условиях эксперимента экзотермическая реакция превращения аморфного оксида в гидроксид, в то время как для хорошо окристаллизованных образцов $\mathrm{Al}_{2} \mathrm{O}_{3}$ эта реакция не наблюдается. Полученные методом РФА данные хорошо согласуются с результатами тепловизионных исследований.

\section{Список литературы}

1. B.G. Vainer, J. Phys. D: Appl. Phys., 41, p. 065102 (2008).

2. B.G. Vainer, ChemPlusChem, 85, p. 1438-1454 (2020). 